This case highlights the importance of recognition of atypical manifestations of SVA, which may lead to missing a definite diagnosis at first assessment. In our case, the patient's primary diagnosis was acute inferior wall MI. This presentation, combined with electrocardopgraphic and coronary angiographic results, can easily mislead the physician to make a definite diagnosis of coronary artery disease and thus ignore further differential diagnosis, without probing into the potential cause of the acute MI. In this case, however, there were some clues. The patient was young, without any cardiometabolic risk factors or any atherosclerotic plaques on echocardiography and angiography, and the exact pathophysiologic mechanism of acute MI thus needed to be determined. Echocardiography plays a key role in the diagnosis of right SVA, determining the location and size of the rupture and demonstrating associated lesions. ${ }^{1}$ Although highly diagnostic, however, echocardiography is limited in both sensitivity and accuracy, especially in an emergency situation. In this case, because the primary impression was coronary artery disease, SVA went unnoticed at first glance, thus demonstrating the importance of including SVA in the differential diagnosis before performing echocardiography on a young individual without any cardiometabolic risks who has a sudden acute MI.

The proposed pathophysiologic mechanism in this case would be that the thrombus developed in the aneurysm of the right coronary sinus of Valsalva and traveled into the RCA once the aneurysm ruptured, in turn precipitating the acute MI. We can tell that the thrombus was not caused by atherosclerosis, because the proximal RCA showed no coronary artery disease changes during the angiographic procedure and the obstruction was very abrupt, thus reinforcing the theory of a thrombus traveling down the RCA. In addition, during an open cardiac procedure, it was observed that neither the SVA nor the right SVA affected the RCA, thus clarifying that the thrombosis of the RCA was related neither to aneurysmal compression of the RCA nor to the right SVA encroaching on the ostium of the RCA. It was also reported that there was thrombosis in the SVA that moved further and might become a source of cerebrovascular embolism, causing a thromboembolic cerebrovascular accident might occur. Shahrabani and colleagues ${ }^{2}$ described a young patient with a large unruptured aneurysm of the right sinus of Valsalva containing thrombus who had a history of cardiovascular accident caused by an embolus to the right middle cerebral artery. Similarly, Honda and coworkers ${ }^{3}$ and Luckraz and colleagues ${ }^{4}$ also reported SVA protruding into the pulmonary artery.

\section{References}

1. Attias D, Messika-Zeitoun D, Cachier A, Brochet E, Serfaty JM, Laissy JP, et al. A multi-perforated man: asymptomatic ruptured sinus of Valsalva aneurysm associated with an atrial and ventricular septal defect. Eur J Echocardiogr. 2008;9:301-2.

2. Shahrabani RM, Jairaj PS. Unruptured aneurysm of the sinus of Valsalva: a potential source of cerebrovascular embolism. Br Heart J. 1993;69:266-7.

3. Honda J, Yonaha T, Nakamura Y, Uechi N, Asato H. Ruptured aneurysm of the sinus of Valsalva protruding into the pulmonary artery. J Thorac Cardiovasc Surg. 2009;137:e37-9.

4. Luckraz H, Naik M, Jenkins G, Youhana A. Repair of a sinus of Valsalva aneurysm that had ruptured into the pulmonary artery. J Thorac Cardiovasc Surg. 2004;127: 1823-5.

\title{
Early structural valve deterioration of the Trifecta aortic valve biological prosthesis: A word of caution
}

\author{
Pankaj Saxena, FRACS, PhD, Kevin L. Greason, MD, and Hartzell V. Schaff, MD, Rochester, Minn
}

The St Jude Medical Inc (St Paul, Minn) Trifecta valve is a relatively new biological prosthesis that completed a multicenter US Food and Drug Administration Investigational Device Exemption study in 2011. During a median patient

From the Division of Cardiovascular Surgery, Mayo Clinic, Rochester, Minn. Disclosures: Authors have nothing to disclose with regard to commercial support. Received for publication April 7, 2013; revisions received July 14, 2013; accepted for publication July 19, 2013; available ahead of print Sept 16, 2013.

Address for reprints: Kevin L. Greason, MD, Division of Cardiovascular Surgery, Mayo Clinic, 200 First St SW, Rochester, MN 55905 (E-mail: greason.kevin@ mayo.edu).

J Thorac Cardiovasc Surg 2014;147:e10-11

$0022-5223 / \$ 36.00$

Copyright (c) 2014 by The American Association for Thoracic Surgery

http://dx.doi.org/10.1016/j.jtcvs.2013.07.053 follow-up of 0.9 years of the 1014 valve implantations in that study, 1 patient underwent explant of the valve for structural valve deterioration. ${ }^{1}$ We report an additional case.

\section{CLINICAL SUMMARY}

A 67-year-old woman presented to us with New York Heart Association class IV dyspnea and severe Trifecta prosthetic aortic valve stenosis. She had multiple previous cardiac operations that included an aortic valve replacement plus coronary artery bypass graft surgery 18 years previously, redo coronary artery bypass graft surgery 13 years previously, and repeat aortic valve replacement with a $21-\mathrm{mm}$ Trifecta valve 4 years previously. 

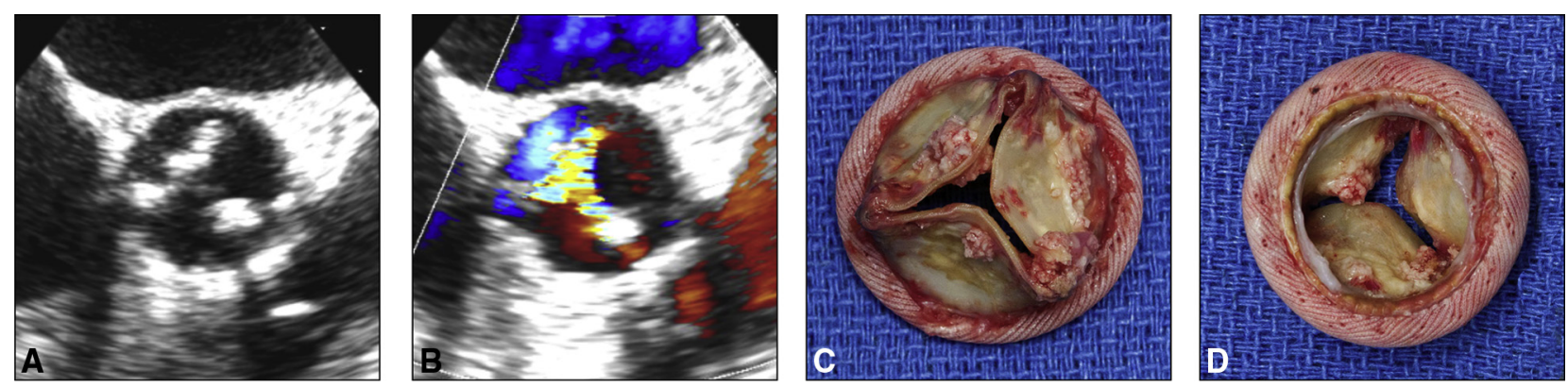

FIGURE 1. A, Intraoperative transesophageal echocardiography in short-axis view demonstrates thickening and calcification of the prosthetic aortic valve cusps. B, Color Doppler demonstrates turbulence across the prosthetic aortic valve due to severe aortic stenosis. C, Explanted valve prosthesis from aortic aspect. D, Explanted valve prosthesis from the ventricular aspect.

She had dysfunction of the Trifecta valve prosthesis with echocardiography that demonstrated severe prosthetic valve stenosis (systolic mean Doppler gradient of $75 \mathrm{~mm} \mathrm{Hg}$ at a heart rate of 55 beats/min and an aortic valve area index of $0.35 \mathrm{~cm}^{2} / \mathrm{m}^{2}$ ) and mild valve regurgitation (Figure $1, A$ and $B)$. The left ventricular systolic ejection fraction was normal. Coronary angiogram demonstrated a patent right internal thoracic artery to left anterior descending coronary artery bypass graft.

The patient's Trifecta valve insertion was performed at another institution, and we do not know the results of her perioperative echocardiogram. Postoperative surveillance transthoracic echocardiograms revealed mean gradients across the prosthetic valve of $6,7,29$, and $46 \mathrm{~mm} \mathrm{Hg}$ at $1,2,3$, and 3.5 years, respectively, after the implantation of the Trifecta valve. The patient was placed on aspirin $325 \mathrm{mg}$ per day at the time of her discharge after the Trifecta valve replacement. The aspirin was continued up to our explant of the Trifecta valve.

The patient underwent repeat sternotomy, bicaval and aortic cannulation, myocardial protection with antegrade and retrograde cardioplegia, and repeat aortic valve replacement. Operative findings confirmed structural valve degeneration of the aortic prosthesis (Figure $1, C$ and $D$ ). We performed supra-annular implantation of a 21-mm Carbomedics Top Hat valve (Sorin Group, Milan, Italy). The patient had an uncomplicated postoperative course and was discharged 5 days after the operation. Postoperative echocardiography demonstrated normal function of the aortic mechanical valve prosthesis and no paravalvular regurgitation.

\section{DISCUSSION}

The use of stented aortic biological prosthetic valves has increased significantly over the last several years because of improvements in valve design and hemodynamics, and satisfactory long-term durability without any need for anticoagulation in the majority of patients. The Trifecta valve is a bovine pericardial valve with promising shortterm results and satisfactory hemodynamics, especially for the small-sized prostheses. ${ }^{1}$ Long-term studies confirm the durability of other pericardial valves in the aortic position with a low probability of explantation. ${ }^{2}$

Structural valve deterioration of a biological prosthesis is an important issue after aortic valve replacement. This phenomenon is not well understood and seems to be multifactorial. Despite the use of anticalcification agents such as glutaraldehyde and ethanol, early degeneration of the valve is still possible from an accelerated immunologic reaction to the pericardial tissue causing valve failure. ${ }^{3}$

Early degeneration of bioprosthetic valves has been reported with other similarly designed pericardial valves implanted in the aortic position. For example, Alvarez and colleageus ${ }^{4}$ reported that $4 \%$ patients in a cohort of 491 patients who had aortic valve replacement with the Mitroflow valve (Model A12; Sorin Group Inc, Mitroflow Division, Vancouver, Canada) underwent reoperation after structural valve deterioration at a median follow-up of 76 months in patients aged more than 70 years. ${ }^{4}$

\section{CONCLUSIONS}

Regular clinical and echocardiographic follow-up of all patients with bioprosthetic aortic valve replacements seems reasonable. We recommend this to detect early and unexpected valve failure. ${ }^{5}$

\section{References}

1. Bavaria JE, Desai ND, Cheung A, Petracek MR, Groh MA, Borger MA, et al The St Jude Medical Trifecta aortic pericardial valve: results from a global, multicenter, prospective clinical study. J Thorac Cardiovasc Surg. March 7, 2013 [Epub ahead of print].

2. Grunkemeier GL, Furnary AP, Wu Y, Wang L, Starr A. Durability of pericardial versus porcine bioprosthetic heart valves. J Thorac Cardiovasc Surg. 2012;144: 1381-6.

3. Manji RA, Zhu LF, Nijjar NK, Rayner DC, Korbutt GS, Churchill TA, et al. Glutaraldehyde-fixed bioprosthetic heart valve conduits calcify and fail from xenograft rejection. Circulation. 2006;114:318-27.

4. Alvarez JR, Sierra J, Vega M, Adrio B, Martinez-Comendador J, Gude F, et al Early calcification of the aortic Mitroflow pericardial bioprosthesis in the elderly. Interact Cardiovasc Thorac Surg. 2009;9:842-6.

5. Fleisher AG, Lafaro RJ, Moggio RA. Immediate structural valve deterioration of 27-mm Carpentier-Edwards aortic pericardial bioprosthesis. Ann Thorac Surg. 2004;77:1443-5. 